\title{
PENGARUH INTENSITAS MUSIM HUJAN TERHADAP KELIMPAHAN FITOPLANKTON DI WADUK BENING SARADAN
}

\author{
Klaudia Putri Nirmalasari, Marheny Lukitasari., Joko Widianto \\ Pendidikan Biologi, Fakultas MIPA, IKIP PGRI MADIUN \\ Email: klaudia_putri@yahoo.co.id/marh33ny@gmail.com
}

\begin{abstract}
This study aims to determine the effect of the intensity of the rainy season to the abundance of phytoplankton in the reservoir Bening Madison County. As well as exploit some results of research on the abundance of phytoplankton as a medium of learning materials were shaped poster on the types of phytoplankton. This study uses a quantitative approach to the exploration technique. There are six points each station with two sample replicates. The results showed that in Reservoir Bening Saradan found 16 species of phytoplankton that is Synedra acus, Synedra ulna, Navicula grevillei, Tetragonodium verum, Crucigenia rectangularis, Ulothrix cylindricum, Nitzchia paleaceae, Ceratium candelabrum, Goniochloris sculpta, Scenedesmus ocuminatus, Navicula sp, Nitzchia acicularis, Spirulina major, Ceratoneis acus, Pediastrum simplex, Pleurota eniumtrabecula. Phytoplankton abundance is the most ubiquitous class Bacillariophyceae. Phytoplankton abundance is influenced by monsoon intensity $40,9 \%$. While $59,1 \%$ of other factors influenced the agricultural wastes that contain elements of $\mathrm{N}, \mathrm{P}, \mathrm{K}$, which can improve nutrient. The highest phytoplankton abundance in December is 138,64 ind/l with 12 species of phytoplankton. The number of rainy days in the December low at 25/31 days allows a maximum of phytoplankton photosynthesis. Lowest phytoplankton abundance in February which is 65,14 ind/l. Phytoplankton abundance is directly proportional to the intensity of the rainy season. The number of higher intensity, phytoplankton abundance is also higher, and vice versa. Physical and chemical conditions Bening Reservoir categorized according to the results of research in the waters of the state are less fertile and less than optimal for the growth of phytoplankton.
\end{abstract}

Keywords : phytoplankton, abundance, intensity of the rainy season

\section{PENDAHULUAN}

Ekosistem akuatik memegang
peranan penting untuk menyediakan
sumber air bagi kehidupan organisme
atau makhluk hidup. Berbagai parameter
saling berpengaruh rerhadap
keberlangsungan hidup organisme air
yang terdiri dari parameter fisika, kimia
dan biologi. Salah satu parameter
biologi yang berperan dalam
menentukan mata rantai kehidupan
organisme di dalam air yakni plankton.
Menurut Kasijan dan Sri (2009:
36) plankton terdiri dari fitoplankton
atau plankton tumbuh-tumbuhan dan
zooplankton atau plankton hewan.
Fitoplankton berperan sebagai produsen

primer yaitu organisme yang dapat mengubah senyawa anorganik menjadi senyawa organik dengan bantuan sinar matahari melalui proses fotosintesis. Kelimpahan fitoplankton penting artinya dalam menentukan kesuburan suatu perairan.

Faktor yang berpengaruh terhadap kelimpahan plankton di perairan adalah musim. Pada musim hujan konsentrasi nutrien akan lebih rendah dibandingkan dengan musim kemarau sehingga densitas planktonnya juga rendah (Moyle, dalam Krismono \& Yayuk 2007: 108). Kondisi ini disebabkan musim penghujan dengan kadar curah hujan yang tinggi memiliki penetrasi 
cahaya, salinitas, suhu yang rendah, serta kekeruhan yang tinggi dibanding musim kemarau.

Salah satu jenis waduk yang terkenal di perbatasan Madiun dan Saradan adalah Waduk Bening yang memiliki luas $860 \mathrm{~km}^{2}$. Perubahan musim khususnya musim hujan dengan intensitas hujan yang berbeda berpengaruh terhadap kualitas dan kuantitas organisme akuatik di dalamnya, sehingga secara tidak langsung akan berpengaruh terhadap produktivitas ikan yang ada di Waduk Bening.

Menurut Rimper (dalam Yaserli, dkk., 2013) kelimpahan fitoplankton terbagi atas 3 kelompok fitoplankton yaitu rendah, sedang dan tinggi. Kelimpahan rendah berkisar $<12.000$ $\mathrm{sel} / \mathrm{l}$, sedang 12.500 sel/l dan kelimpahan fitoplankton tinggi > 17.000 sel/l. Jumlah spesies dan kelimpahan yang bervariasi mempengaruhi indeks keanekaragamannya.

Kelimpahan plankton di musim hujan maupun di musim kemarau berbeda, karena sifat fisik dan kimia dalam perairan mengalami perubahan akibat perbedaan musim. Pada musim hujan konsentrasi nutrien akan lebih rendah bila dibandingkan dengan musim kemarau sehingga densitas planktonnya juga rendah (Moyle, dalam Krismono \& Yayuk 2007: 111). Musim berkaitan erat dengan curah hujan yang turun sepanjang tahun. Menurut BMG (dalam

\section{METODE PENELITIAN}

Lokasi penelitian pengambilan sampel adalah di Waduk Bening Desa Pajaran Kecamatan Saradan Kabupaten Madiun Provinsi Jawa Timur. Waduk Bening oleh masyarakat difungsikan untuk aktivitas pertanian, PLTA, perikanan, wisata, camping dan ritual budaya. Identifikasi dan penghitungan kelimpahan fitoplankton dilakukan di Laboratoriun Biologi IKIP PGRI
Aang, dkk., 2008: 3) musim penghujan dimulai jika intensitas curah hujan lebih dari $150 \mathrm{~mm}$ per bulan. Musim kemarau didefinisikan sebagai periode dimana jumlah curah hujan bulanan kurang dari $50 \mathrm{~mm}$ (BMG, dalam Bayong, dkk., 2009: 4).

BMKG (2014) membagi intensitas musim hujan menjadi 4 kategori hujan diantaranya yakni : dikatakan hujan ringan dengan rentang 1 - $5 \mathrm{~mm} / \mathrm{jam}$, hujan sedang dengan rentang $5-10 \mathrm{~mm} / \mathrm{jam}$, hujan lebat dengan rentang $10-20 \mathrm{~mm} / \mathrm{jam}$, dan hujan sangat lebat apabila $>20 \mathrm{~mm} / \mathrm{jam}$. Siklus musim yang terjadi di negara 2 musim maupun 4 musim prinsipnya sama karena mengakibatkan perubahan jumlah plankton. Penelitian yang dilakukan Henry di danau Jurumirim (dalam Nogueira, 2000: 126) menyatakan bahwa tingginya kelimpahan kelompok fitoplankton di musim dingin dikaitkan dengan interaksi alga dan unsur hara. Pertumbuhan fitoplankton musim dingin terkait dengan retensi air lebih lama (cuaca kering), maupun sirkulasi internal nutrisi karena tidak adanya termoklin (Nogueira, 2000: 127). Diperkuat oleh penelitian yang dilakukan Zeng et al (2006: 1001) pada tiga jenis danau yang berbeda. Jenis fitoplankton di musim hujan terdiri dari Diatom, Chlorophyta, Cryptophyta, Cyanophyta dan Pyrrophyta.

Madiun. Penelitian dimulai bulan Desember - Februari 2014.

\section{Prosedur Pengambilan Sampel}

Langkah-langkah pengambilan sampel adalah sebagai berikut. Alat yang digunakan yakni plankton net 80 $\mu \mathrm{m}$, botol flakon, botol gelap, ember 3 liter, bolpoin. Bahan yang digunakan yakni formalin $4 \%$.

Prosedur kerja yang digunakan yakni mengambil sampel air secara vertikal dan horizontal dapat dilakukan dengan ember plastik kapasitas 3 liter. 
Sampel diambil sebanyak 30 liter dan disaring dengan jaring plankton (plankton net). Air yang tertampung dalam botol penampung dipindahkan ke dalam botol flakon yang bersih, berlabel dan diberi larutan pengawet formalin 4\% (Satino, 2010: 17).

\section{Analisis Hasil Sampling}

Kegiatan pengamatan fitoplankton dilakukan di Laboratoriun Biologi IKIP PGRI Madiun. Identifikasi fitoplankton melalui bentuk tubuh berbentuk koloni dan multiseluler, adanya dinding sel atau cangkang (Kimball, dalam Linda dan Trisna 2009: 2). Penentuan kelimpahan fitoplankton dihitung menggunakan rumus menurut Sachlan dan Effendie (dalam Madinawati, 2010: 120) yakni : $\mathrm{N}=\mathrm{n}\left(\frac{\text { Volume Air Tersaring (Vr) }}{\text { Volume Air Yang Diamati (Vo) }}\right) \times\left(\frac{1}{\text { Volume Air Yan }}\right.$

\section{HASIL DAN PEMBAHASAN}

Hasil perhitungan kelimpahan fitoplankton selama 3 bulan dapat diamati pada Tabel 1 berikut ini.

Tabel.1. Kelimpahan Fitoplankton di Waduk Bening Selama Musim Hujan

\begin{tabular}{|l|c|l|}
\hline \multirow{2}{*}{$\begin{array}{c}\text { Bulan } \\
\text { Pengambilan }\end{array}$} & \multicolumn{2}{|c|}{$\sum$ Kelimpahan } \\
\cline { 2 - 3 } Desember & $\begin{array}{c}\text { Kelimpahan } \\
\text { ind/1 }\end{array}$ & $\sum$ Spesies \\
\hline Januari & $\begin{array}{l}113,16 \\
\text { ind/1 }\end{array}$ & 12 Spesies \\
\hline Februari & $\begin{array}{l}65,14 \\
\text { ind/1 }\end{array}$ & 6 Spesies \\
\hline
\end{tabular}

Data intensitas curah hujan di Waduk Bening didapatkan dari BMKG stasiun Geofisika Nganjuk selama dari (Badan Meteorologi dan Geofisika) bulan Desember - Februari 2014.

Tabel 2. Data Curah Hujan di Waduk Bening

\begin{tabular}{|l|c|c|c|}
\hline Bulan & $\begin{array}{c}\text { Hari } \\
\text { Hujan }\end{array}$ & $\begin{array}{c}\text { Intensitas } \\
\text { Hujan }\end{array}$ & urah Hujan \\
\hline Desember & $25 / 31$ & 20,24 & 506,0 \\
& hari & $\mathrm{mm} / \mathrm{jam}$ & $\mathrm{mm} / \mathrm{bulan}$ \\
\hline Januari & $\begin{array}{c}31 / 31 \\
\text { hari }\end{array}$ & $\begin{array}{c}17,83 \\
\mathrm{~mm} / \mathrm{jam}\end{array}$ & $\begin{array}{c}553,0 \\
\mathrm{~mm} / \mathrm{bulan}\end{array}$ \\
\hline Februari & $\begin{array}{c}28 / 28 \\
\text { hari }\end{array}$ & $\begin{array}{c}15,75 \\
\mathrm{~mm} / \mathrm{jam}\end{array}$ & $\begin{array}{c}441,0 \\
\mathrm{~mm} / \mathrm{bulan}\end{array}$ \\
\hline
\end{tabular}

Berikut hasil penelitian hubungan kelimpahan fitoplankton selama 3 bulan pengamatan (Desember - Februari 2014) di Waduk Bening Saradan disajikan pada gambar 1 berikut. 


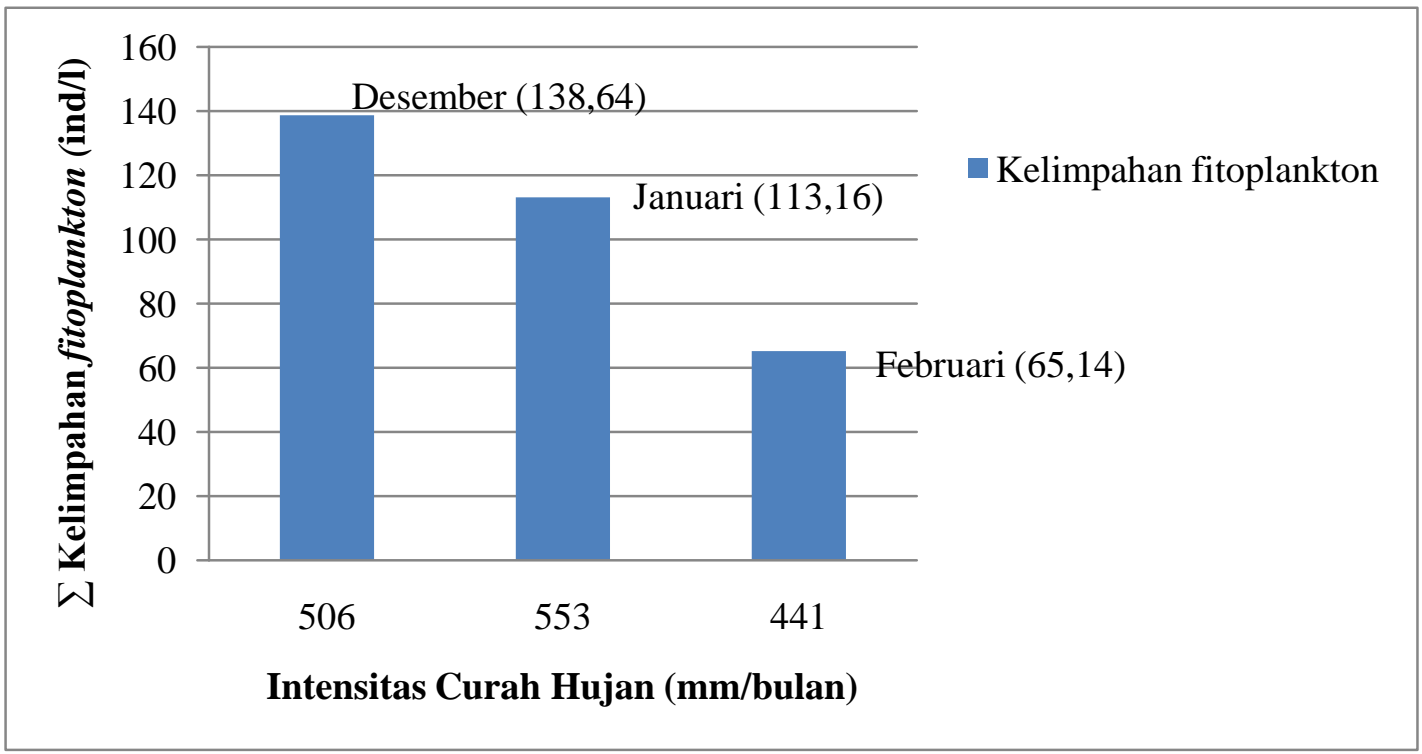

\section{Gambar 1. Hubungan Intensitas Musim Hujan Terhadap Kelimpahan Fitoplankton di Waduk Bening}

Gambar 1. menunjukkan hubungan intensitas musim hujan terhadap kelimpahan fitoplankton di Waduk Bening. Intensitas hujan selama 3 bulan (Desember - Februari 2014) di Waduk Bening memiliki rata-rata berkisar $15,75-20,24$ $\mathrm{mm} / \mathrm{jam}$. Intensitas hujan tersebut tergolong intensitas hujan yang lebat karena memiliki rentang $10-20 \mathrm{~mm} / \mathrm{jam}$ sehingga nilai curah hujannya tinggi mencapai > $250 \mathrm{~mm} / \mathrm{bulan}$. Sesuai pendapat BMKG (2014) yang diperkuat dengan Erwin (2002: 3) bahwa bulan Desember - Februari terjadi peningkatan curah hujan di atas $250 \mathrm{~mm} /$ bulan dengan intensitas hujan $10-20 \mathrm{~mm} / \mathrm{jam}$ yang merupakan intensitas hujan lebat.

Rata-rata hasil penghitungan kelimpahan fitoplankton selama 3 bulan (Desember - Februari 2014) menunjukkan hasil < 12.000 sel/l, sehingga dapat dikatakan kelimpahan fitoplankton tergolong rendah. Sesuai dengan pendapat Rimper (dalam Yaserli, dkk., 2013) yang mengatakan bahwa kelimpahan fitoplankton rendah berkisar < $12.000 \mathrm{sel} / \mathrm{l}$. Hal tersebut dikarenakan pada musim hujan konsentrasi nutrien akan lebih rendah dibandingkan musim kemarau dengan densitas plankton yang juga rendah
(Moyle, dalam Krismono \& Yayuk 2007: 111). Kondisi ini disebabkan musim penghujan dengan kadar curah hujan yang tinggi memiliki penetrasi cahaya, salinitas, suhu yang rendah, serta kekeruhan yang tinggi dibanding musim kemarau.

Hasil analisis regresi menunjukkan ada pengaruh yang signifikan antara intensitas musim hujan terhadap kelimpahan fitoplankton di Waduk Bening. Hal ini ditunjukkan dengan hasil pengolahan data menggunakan regresi menunjukkan nilai probabilitas < 0,05 yakni 0,025. Besarnya pengaruh intensitas musim hujan terhadap kelimpahan fitoplankton sebesar 40,9 \%. Artinya kelimpahan fitoplankton di Waduk Bening pada musim hujan dipengaruhi oleh intensitas musim hujan sebesar 40,9\%. 59,1\% kelimpahan fitoplankton di Waduk Bening dipengaruhi oleh faktor lain. Faktor lain sebesar $59,1 \%$ yang berpengaruh terhadap kelimpahan fitoplankton yakni aktivitas masyarakat di sekitar Waduk Bening. Salah satunya yakni kegiatan pertanian. Secara tidak langsung limbah pertanian seperti sisa pupuk, pestisida yang mengandung $\mathrm{N}, \mathrm{P}, \mathrm{K}$ mengalir menuju sungai Petung dan masuk bermuara di Waduk Bening. Adanya kandungan 
phospor, nitrogen dalam limbah tersebut digunakan sebagai penyedia utama nutrisi yang dibutuhkan fitoplankton untuk pertumbuhannya (Hendrawan, dalam Madinawati 2010: 121). Akibatnya terjadi peningkatan kuantitatif spesies fitoplankton yakni kelas Bacillariophyceae yang mengakibatkan berkurangnya jenis spesies lain karena terjadi persaingan penggunaan oksigen terlarut.

Spesies fitoplankton dengan kelimpahan tertinggi dan mendominasi di Waduk Bening selama 3 bulan penelitian (Desember - Februari 2014) dapat dilihat pada Gambar 2 berikut.

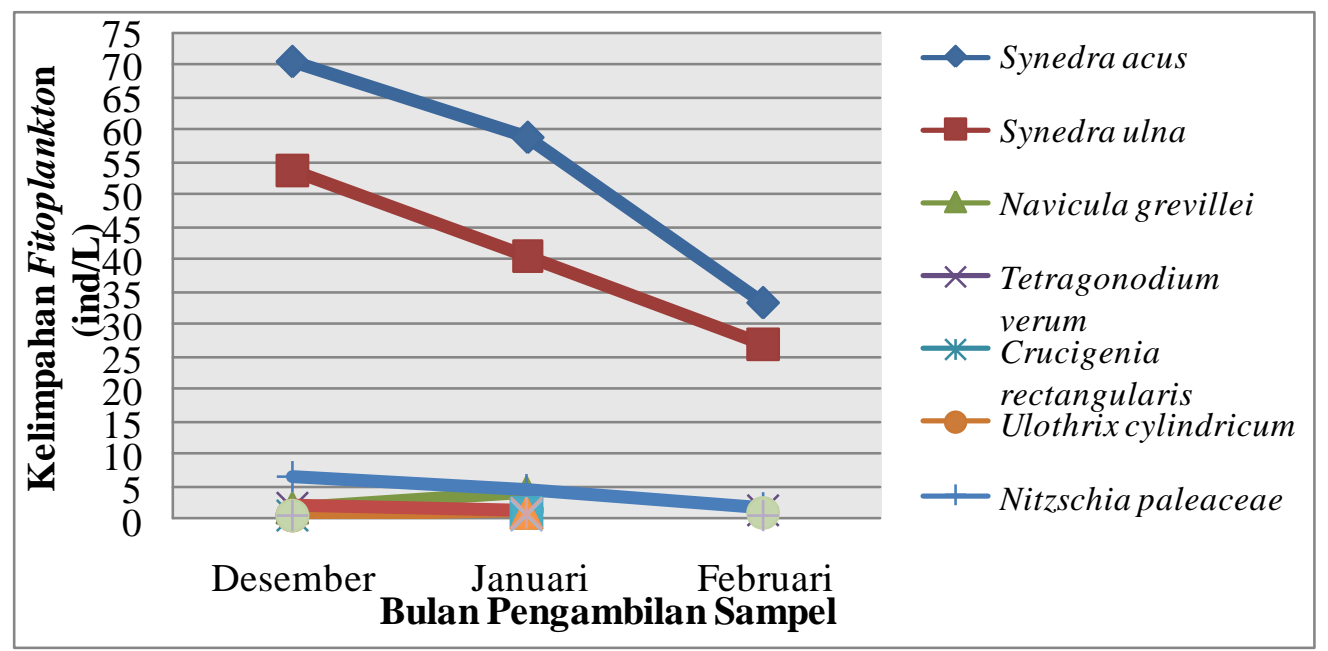

Gambar 2. Kelimpahan Spesies Fitoplankton di Waduk Bening Selama Musim Hujan

Gambar 2 menunjukkan kelimpahan spesies fitoplankton yang ditemukan di Waduk Bening selama 3 bulan (Desember - Februari 2014) berasal dari kelas Bacillariophyceae. Kelas Bacillariophyceae mampu bertahan dalam kondisi perairan yang ekstrim karena mempunyai sifat kosmopolit, mudah beradaptasi dan mempunyai daya reproduksi yang tinggi (Sachlan, dalam Krismono \& Yayuk 2007: 110). Sifat fisik dan kimia perairan di Waduk Bening selama 3 bulan penelitian (Desember Februari 2014 dapat diamati pada Gambar 3 berikut

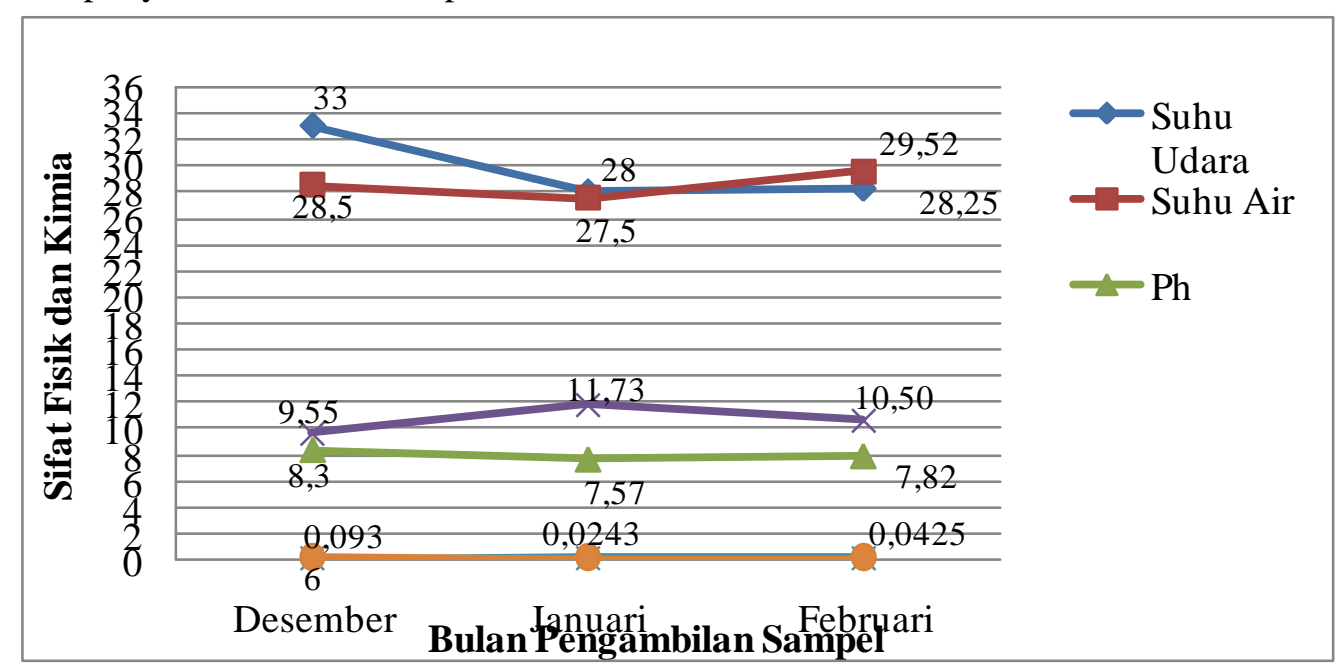

Gambar 3. Sifat Fisik dan Kimia Perairan di Waduk Bening 
Gambar 3 menunjukkan sifat fisik dan kimia di Waduk Bening selama 3 bulan pengamatan. Nilai $\mathrm{pH}$ sebesar 7 8,3 . Nilai $\mathrm{pH}$ tersebut termasuk dalam kategori tinggi dan menunjang untuk pertumbuhan fitoplankton yang maksimal. Sesuai dengan pendapat Soesono (dalam Suryanti, dkk., 2013: 44) yang menyatakan bahwa $\mathrm{pH}$ yang tinggi $(7,0$ $9,0)$ merupakan perairan yang produktif yang berperan mendorong proses pembongkaran bahan organik dalam air menjadi mineral-mineral yang dapat diasimilasikan oleh fitoplankton. Hasil pengukuran DO selama 3 bulan menunjukkan nilai yang cukup tinggi dan layak untuk kehidupan mahluk hidup akuatik yakni 9,55 - 11,73. Wardoyo (dalam Iin, dkk., 2014: 35) menyatakan bahwa kehidupan ikan dan kebanyakan organisme perairan lainnya masih dapat hidup dengan layak jika kandungan oksigen terlarut perairan lebih besar dari 3 $\mathrm{mg} / \mathrm{l}$.

Kadar nitrat $\left(\mathrm{NO}_{3}\right)$ di Waduk Bening selama 3 bulan pengamatan menunjukkan hasil berkisar dari 0,0186 - 0,0501 $\mathrm{mg} /$ liter. Kondisi tersebut mengisyaratkan bahwa perairan di Waduk Bening dapat digunakan untuk kehidupan mahluk hidup akuatik. Sesuai dengan pendapat Dewi (2009: 11) yang menyatakan bahwa kadar nitrat-nitrogen pada perairan alami hampir tidak pernah lebih dari $0,1 \mathrm{mg} / \mathrm{liter}$. Kadar nitrat yang terkandung di perairan Waduk Bening sebagai akibat dari aktivitas pertanian yang dilakukan di sekitar Waduk Bening yang menimbulkan limbah seperti

\section{KESIMPULAN DAN SARAN}

\section{A. KESIMPULAN}

Dari analisis dalam pembahasan dapat disimpulkan bahwa :

1. sifat fisik dan kimia selama musim hujan di Waduk Bening tidak optimal menunjang pertumbuhan fitoplankton.

2. Terdapat pengaruh yang signifikan antara intensitas musim hujan terhadap kelimpahan fitoplankton sisa pestisida, pupuk yang mengandung unsur N, P, K. Diperkuat dengan pernyataan Environtment Canada (dalam Fonny \& Hanif, 2011: 139) bahwa peningkatan kadar nitrat umumnya dari limbah perkotaan, industri, dan pertanian.

Hasil pengukuran kadar ammonium $\left(\mathrm{NH}_{4}\right)$ di Waduk Bening selama 3 bulan berkisar dari $0,0243-0,0936 \mathrm{mg} / \mathrm{liter}$. Hasil pengukuran kadar ammonium $\left(\mathrm{NH}_{4}\right)$ menunjukkan bahwa kondisi perairan di daerah Waduk Bening didominasi oleh unsur ammonium $\left(\mathrm{NH}_{4}\right)$ daripada nitrat. Hal ini menunjukkan perairan di Waduk Bening tergolong perairan yang tercemar dan kurang subur. Diperkuat dengan pendapat Dewi (2009: 11) yang mengatakan bahwa kadar nitrat di perairan yang tidak tercemar biasanya lebih tinggi daripada kadar amonium. Ditunjang dengan rata-rata perhitungan kelimpahan fitoplankton selama musim hujan yang menunjukkan hasil < 12.000 sel/l, sehingga dapat dikatakan kelimpahan fitoplankton tergolong rendah. Selain itu dominansi jenis fitoplankton tertentu yakni dari kelas Bacillariophyceae mengindikasikan ketidakseimbangan kondisi perairan di Waduk Bening karena adanya limbah pertanian yang masuk di waduk. Diperkuat menurut pendapat Soedarti (dalam Madinawati, 2010: 122) yang menyatakan bahwa munculnya fitoplankton yang dominan dan tidak dominan dalam suatu komunitas perairan menyebabkan perairan tersebut tidak seimbang akibat pencemaran dari buangan limbah ke perairan.

di Waduk Bening dengan nilai probabilitas $<0,05$ yakni 0,025 .

3. Pengaruh intensitas musim hujan terhadap kelimpahan fitoplankton sebesar 40,9\%. 59,1\% kelimpahan fitoplankton di Waduk Bening dipengaruhi oleh faktor lain yakni aktivitas dalam bidang pertanian oleh masyarakat sekitar. 


\section{B. SARAN}

Masyarakat dan pengunjung Waduk Bening perlu memperhatikan aktivitas di sekitar lingkungan Waduk Bening seperti pertanian, pariwisata yang dilakukan. Tujuannya agar kualitas perairan Waduk Bening tetap terjaga.

\section{DAFTAR RUJUKAN}

Aang Anshorullah, Endang Widyastuti dan Asrul Sahri Siregar. 2008. Distribusi Diatomae Planktonik Pada Musim Yang Berbeda di Perairan Waduk Wadaslintang Wonosobo. Prosiding Seminar Nasional Limnologi IV. (http://Fakultas Biologi UNSOED /prosiding/article/view, Diunduh 10 Februari 2014).

Bayong, dkk. 2009. Dampak Variansi Temperatur Samudra Pasifik dan Hindia Ekuatorial Terhadap Curah Hujan di Indonesia. Jurnal Limnologi (Online), (http://ejournal.limnologi.ac.id , Diunduh 18 Januari 2014).

BMKG. 2014. Badan Meteorologi Klimatologi dan Geofisika. http://BMKG.go.id, Diunduh 18 Februari 2014)

Hui Zeng, et al. 2006. Distribution of phytoplankton in the Three-Gorge Reservoir during rainy and dry seasons. Science of the total environment (Online), 999-1009, (http://www.sciencedirect.com, Diunduh 15 Januari 2014).

Kasijan Romimohartarto dan Sri Juwana. 2009. Biologi Laut: Ilmu Pengetahuan Tentang Biota Laut. Jakarta: Djamabatan.

Krismono dan Yayuk Sugianti. 2007. Distribusi Plankton di Waduk Kedungombo Plankton Distribution in Kedungombo Reservoir. Jurnal Perikanan, Hal 108-115, (http:// jurnal Perikanan. ac.id, Diunduh 13 Januari 2014).

Marcos Gomes Nogueira. 2000.
Phytoplankton composition,
dominance and abundance as
indicators of environmental
compartmentalization in
Jurumirim Reservoir
(Paranapanema River), São Paulo,
Brazil. Kluwer Academic
Publishers (Online), 1479-1490,
(http://www.sciencedirect.com,
Diunduh 15 Januari 2014).

